\title{
DINÂMICA DA EXPANSÃO DA CANA-DE-AÇÚCAR NA MICRORREGIÃO GEOGRÁFICA DE ITUIUTABA-MG
}

\author{
Matheus Eduardo Souza Teixeira \\ Universidade Federal de Uberlândia (UFU) \\ Instituto de Geografia, Pós-Graduação em Geografia, Uberlândia, MG, Brasil \\ matheuseduardo002@gmail.com \\ Roberto Barboza Castanho \\ Universidade Federal de Uberlândia (UFU) \\ Instituto de Ciências Humanas do Pontal, Pós Graduação em Geografia do Pontal, Ituiutaba, MG, Brasil

\begin{abstract}
RESUMO
Este estudo objetivou analisar a expansão da cana-de-açúcar na MRG de Ituiutaba-MG e suas implicações territoriais decorrentes deste processo. Para tanto, os procedimentos metodológicos foram divididos em: a) revisão bibliográfica; b) coleta e tabulação de dados de produção de cana-de-açúcar; c) trabalho de campo na MRG de Ituiutaba; d) análises e redação final da pesquisa. Verificou-se que a expansão do setor sucroenergético na MRG de Ituiutaba ocorre inicialmente com o Proálcool e, a partir dos anos 2000, o aumento do setor de forma significativa esteve relacionada principalmente com a ampliação geral da produção de commodities no Brasil, as implicações do Protocolo de Kyoto, a produção de automóveis flex fuel e o financiamento do BNDES. A presença de duas usinas sucroenergéticas também corrobora para a expansão do setor na microrregião, que não apenas aciona as terras dos municípios em que estão inseridas, mas também em municípios do entorno, sobretudo pela necessidade de capturar grandes extensões de terras para suprir sua demanda de processamento da unidade industrial. Portanto, a expansão do setor sucroenergético na MRG de Ituiutaba está intimamente ligada às ações do Estado, que estimularam a produção de cana-de-açúcar em diversas porções territoriais e também pela inserção das usinas na região.
\end{abstract}

Palavras-chave: Cana-de-açúcar. Políticas públicas. MRG de Ituiutaba.

\section{DIÁMICA DE LA EXPANSIÓN DE LA CANA DE AZÚCAR EN LA MICRORREGIÓN GEOGRÁFICA DE ITUIUTABA-MG}

\begin{abstract}
RESUMEN
Este estudio tuvo como objetivo analizar la expansión de la caña de azúcar en el MRG de Ituiutaba-MG y sus implicaciones territoriales derivadas de este proceso. Para ello, los procedimientos metodológicos se dividieron en: a) revisión bibliográfica; b) recopilación y tabulación de datos de producción de caña de azúcar; c) trabajo de campo en MRG en Ituiutaba; d) análisis y redacción final de la investigación. Se encontró que la expansión del sector azucarero-energético en MRG de Ituiutaba ocurre inicialmente con Proálcool y, desde la década de 2000, el aumento del sector de manera significativa estuvo relacionado principalmente con la expansión generalizada de la producción de commodities en Brasil, las implicaciones de Protocolo de Kioto, producción de automóviles flex fuel y financiamiento de BNDES. La presencia de dos centrales azucareras también corrobora la expansión del sector en la microrregión, que no solo activa los terrenos de los municipios en los que operan, sino también de los municipios aledaños, principalmente por la necesidad de captar grandes extensiones de terreno para abastecer su demanda de procesamiento de la unidad industrial. Por tanto, la expansión del sector azucarero-energético en el MRG de Ituiutaba está estrechamente ligada a las acciones del Estado, que estimuló la producción de caña de azúcar en varias porciones territoriales y también por la inserción de las plantas en la región.
\end{abstract}

Palabras clave: Caña de azúcar. Políticas públicas. MRG de Ituiutaba. 


\section{INTRODUÇÃO}

A inserção da técnica na agricultura, principalmente a partir da década de 1960, período marcado pelas ações do Estado para a modernização agrícola e também pela Revolução Verde, resultou em mudanças no modelo de produção. Tais mudanças promoveram um rearranjo na dinâmica agrária do Brasil, estimulando a expansão de culturas voltadas para a exportação, como a soja e a cana-de-açúcar, seja na forma de matéria-prima ou como subproduto (açúcar). Além disso, é possível observar uma ampliação dos espaços de produção, bem como da produtividade, atreladas ao uso intensivo de maquinários, agrotóxicos, sementes transgênicas, entre outros.

Estas mudanças nos espaços agrícolas, marcadas pela inserção da técnica, ciência e informação norteadas e muito amparadas pelo Estado, privilegiaram o chamado agronegócio e impulsionaram a inserção da produção agrícola nacional no mercado mundial. Tais condições é possível de ser analisada para a canade-açúcar, sobretudo pela quantidade significativa que esta produção ocupa no território nacional, ficando atrás apenas da soja.

Ressalta-se que a produção de cana-de-açúcar no Brasil faz-se presente desde que o país era colônia de Portugal, momento em que essa cultura começou a ser implantada para satisfazer às demandas da potência europeia por açúcar, na qual até então se utilizava o açúcar de beterraba na ocasião.

No cenário atual, a cana-de-açúcar apresenta números expressivos no território brasileiro, dobrando a produção de cana entre 2000 e 2012, movimento este que é acompanhado por ações do Estado que estimularam esta produção, além de expressivo ingresso de agentes estrangeiros no setor. Neste sentido, novos grupos, bem como investidores de ordem global se inseriram no processo produtivo dos derivados de cana-de-açúcar, através de fusões e aquisições de usinas.

Diante das ações do Estado, o país conhece significativa expansão do cultivo da cana-de-açúcar, especialmente em função do aumento das demandas internacionais por açúcar e das possibilidades de afirmação do etanol como combustível renovável (fruto das preocupações com o aquecimento global que se afirmam no final do século XX), bem como da tecnologia flex fuel que hoje compreende a maior parte da frota nacional de veículos.

A Microrregião Geográfica (MRG) de Ituiutaba-MG (recorte espacial de análise) também acompanha o processo de expansão da cana-de-açúcar juntamente com o estado de Minas Gerais e outras partes do território nacional, sendo que, atualmente, a referida região possui três usinas sucroenergéticas em funcionamento.

A primeira usina sucroenergética está inserida no município de Santa Vitória (usina Santa Vitória - início das atividades em 2008), uma no município de Capinópolis (usina Vale do Paranaíba - retomada da produção em 2020) e outra localizada no município de Ituiutaba (usina BP Bunge - início das atividades em 2011), sendo elas as responsáveis pelo beneficiamento de quase toda a produção de cana-de-açúcar da microrregião.

Vale ressaltar que a virada do século é marcada por uma profunda modificação na estrutura produtiva agrícola da MRG de Ituiutaba, orientada, sobretudo, pelos estímulos governamentais e também pelas instalações das usinas sucroenergéticas, resultando na ampliação expressiva da cana-de-açúcar no recorte espacial mencionado. Neste sentido, este estudo objetivou analisar a expansão da cana-de-açúcar na MRG de Ituiutaba-MG e suas implicações territoriais decorrentes deste processo.

Portanto, para entender a expansão da cana-de-açúcar na MRG de Ituiutaba é necessário apontar dois pontos, sendo o primeiro os incentivos do Estado para os estímulos na atividade sucroenergética, sobretudo para a produção do etanol e, também, pela inserção das usinas sucroenergéticas que se instalaram na MRG de Ituiutaba-MG que expandiram essa monocultura, objetivando a produção de açúcar, etanol e a geração energia elétrica.

\section{MATERIAIS E MÉTODOS}

Os procedimentos metodológicos que nortearam esta pesquisa, foram divididos em algumas etapas: inicialmente, elaborou-se uma revisão bibliográfica acerca da temática; em seguida, realizou-se uma coleta, tabulação e análises dos dados de produção de cana-de-açúcar, sendo estes dados coletados pela PAM (Produção Agrícola Municipal); após estas etapas, fez-se um trabalho de campo na MRG de Ituiutaba para analisar a dinâmica da produção de cana-de-açúcar, bem como relacionar este processo com as influências das usinas sucroenergéticas inseridas no recorte espacial estudado; por fim, realizou-se a sistematização e a redação final da pesquisa. 
A MRG de Ituiutaba (MG) localiza-se na parte noroeste do Triângulo Mineiro, no estado de Minas Gerais e no território brasileiro. A MRG é formada por seis municípios, sendo: Ituiutaba, Santa Vitória, Gurinhatã, Capinópolis, Cachoeira Dourada e Ipiaçu, conforme aponta a figura 1.

Figura 1 - Localização da Microrregião Geográfica de Ituiutaba - MG, 2019.

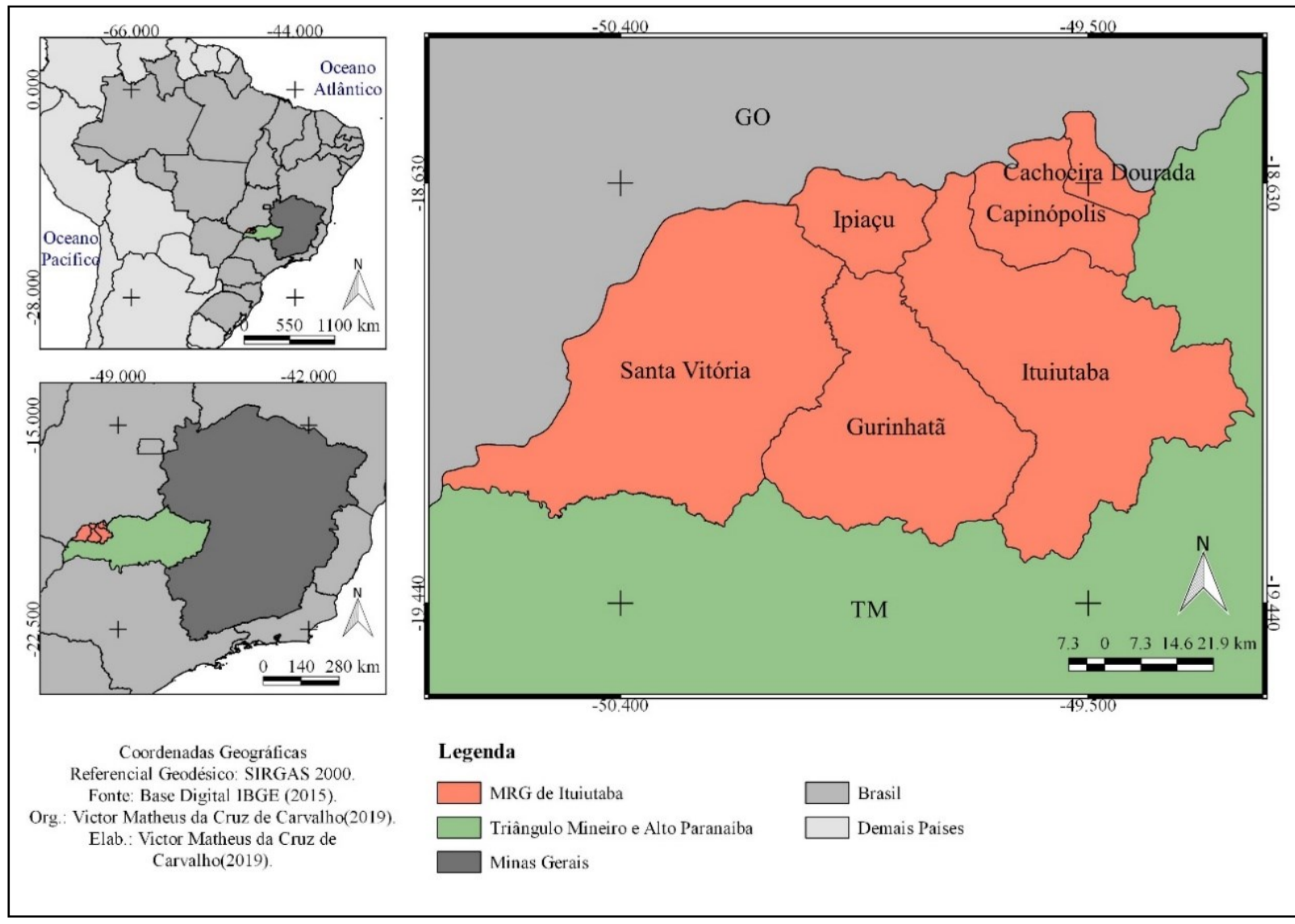

A MRG de Ituiutaba é formada por uma área total de 8.736,204 km2, com uma densidade demográfica de 16,41 habitantes por quilômetro quadrado, perfazendo, assim, os seis municípios que compõe a MRG de Ituiutaba.

Faz-se necessário ressaltar que a MRG de Ituiutaba-MG desenvolve diversas atividades primárias, em que, através de dados do IBGE, pode-se aferir que a cana-de-açúcar vem ganhando números relevantes neste início de século. Portanto, é preciso investigar como ocorre a dinâmica deste processo, bem como identificar os principais agentes que permitiram tais transformações territoriais.

Para além da introdução, dos materiais e métodos e das considerações finais, este artigo encontra-se dividido em duas seções. A primeira parte avalia a expansão do setor sucroenergético no território nacional, especialmente a partir das políticas governamentais - principal fomentador deste processo. Já a segunda seção revela como ocorre a ampliação do setor sucroenergético na MRG de Ituiutaba-MG e as implicações territoriais deste processo, sobretudo a partir das instalações das unidades industriais de cana-de-açúcar.

\section{OS CENÁRIOS QUE ESTIMULARAM A EXPANSÃO NA PRODUÇÃO DO SETOR SUCROENERGÉTICO}

A expansão do setor canavieiro está atrelada diretamente com a história do Brasil, uma vez que esteve constituído por um longo período como produto central da economia colonial, sendo que sua influência extrapola o plano econômico, determinando, em boa parte, a evolução social e política do país. Nos dias atuais, a agroindústria canavieira mantém posição de destaque na economia nacional, com o açúcar figurando entre os principais produtos na pauta de exportação e com o álcool (anidro e hidratado) no mercado interno, consumidos como combustível, puro ou adicionado à gasolina (LOCATEL; AZEVEDO, 2008). 
Ressalta-se que o setor canavieiro foi um dos que mais se modificou nesse processo que, inicialmente, teve o Estado como o principal fomentador. O avanço da produtividade agrícola e do rendimento gerado pelos investimentos destinados ao setor eram algumas das finalidades dessas ações estatais, que previam também a redução da dependência externa de commodities originadas a partir dessa produção (MORAES, 2007).

Nessa perspectiva, o Estado surge como uma engrenagem essencial para a expansão da fronteira da canade-açúcar, uma vez que, fomentou políticas públicas que tiveram papéis decisivos para que os números de produção dessa cultivar assumissem elevada magnitude.

Neste viés, Locatel e Azevedo (2008, p. 3) apontam:

\begin{abstract}
Sabe-se que essa política energética não é novidade no Brasil. Desde o início da década de 1970, o Estado brasileiro mantém uma política de incentivos para o setor agroindustrial de produção de álcool combustível (etanol), com a implantação do Proálcool. Cabe ressaltar que desde o início, este Programa foi concebido para beneficiar os usineiros que dispunham de poder político e de uma estrutura de organização capaz de colocar o aparato do Estado funcionando de acordo com seus interesses, carreando recursos para o setor. Nesse sentido, até mesmo técnicos do governo admitem que o setor de produção de álcool é concentrador de renda.
\end{abstract}

Com o objetivo de aproveitar as economias de escopo advindas dos subprodutos da produção de açúcar, aliado com a necessidade crescente de buscar fontes alternativas de combustíveis para reduzir a dependência do petróleo, estabeleceu-se os fatores chave para a inserção de um amplo programa de combustível renovável. Diante do exposto, houve uma busca por um crescimento sustentável e também por um produto economicamente viável, em um contexto de crescentes preocupações com os recursos naturais não renováveis, colocando novamente o etanol em posição de destaque (TONIN; TONIN, 2014).

Desta forma, o governo brasileiro adotou medidas de políticas de produção de bicombustíveis num cenário em que alternativas de produção de energia começaram a ganhar visibilidade. Foi neste contexto que surgiu o Proálcool (Programa Nacional do Álcool), criado em 1975, logo após a crise do petróleo em 1973, a fim de substituir os derivados de petróleo em larga escala, principalmente nos setores energéticos.

Ainda na perspectiva do Proálcool, Cruz et al. (2016, p. 12) destacam:

Em 14 de novembro de 1975, por meio do Decreto n. 76.593, o governo brasileiro criou o Programa Nacional do Álcool (Proálcool)1. Essa ação governamental, motivada principalmente pela súbita elevação dos preços do petróleo (primeiro choque do petróleo), representou um marco no processo de desenvolvimento econômico e social no Brasil. Até então, a imagem da cana-de-açúcar estava ligada a uma economia atrasada, marcada por relações sociais que se faziam objeto de pesquisa de sociólogos e historiadores.

Com a criação do Proálcool, houve uma dinamização do setor agroindustrial canavieiro, em que estavam atrelados a dois problemas graves, sendo o primeiro a crise energética do modelo de desenvolvimento brasileiro, motivado pelo aumento dos preços do petróleo em 1973, e o segundo, foi a crise conjuntural apresentada pelo segmento produtor de açúcar, devido à forte queda do preço do produto no mercado internacional. Destaca-se que na realidade, desde o começo este programa foi idealizado no intuito de beneficiar os usineiros que tinham um poder político, bem como uma estrutura de organização capaz de colocar o aparato do Estado funcionando de acordo com seus interesses, carreando recursos para o setor (LOCATEL; AZEVEDO, 2008).

Mesmo antes de se implementar o Proálcool, o Brasil já era um relevante produtor de cana-de-açúcar, moendo cerca de 68,3 milhões de toneladas de cana por ano e produzindo cerca 5,9 milhões de toneladas de açúcar, embora a produção de etanol combustível fosse pouca, média de 555,6 milhões de litros, dos quais 232,6 milhões de litros de etanol anidro e 323,0 milhões de litros de etanol hidratado (NASTARI, 1983).

Na primeira fase do Proálcool (1975-1979), o álcool que se produzia em destilarias anexas às usinas de açúcar, era o do tipo "anidro", ou seja, desidratado, o que permitia a mistura com a gasolina. A produção de álcool cresceu de 600 milhões de litros por ano em 1975-1976 para 3,4 bilhões de litros por ano em 19791980 (CRUZ et al., 2016).

Vale ressaltar que, a medida do governo em 1931 também foi fundamental para os primeiros olhares em relação à expansão da cana-de-açúcar, em especial na produção do etanol. 
Em 1931, com o Decreto-Lei n. 19.717, passa a ser obrigatório adicionar álcool de cana a toda gasolina no Brasil. O teor de álcool, embora limitado a 5\%, variou ao longo do tempo até a década de 1970 na faixa de zero a 5\%, em função da disponibilidade do álcool. Durante a Segunda Guerra Mundial, com a gasolina importada em falta, há relatos de uso de teores de álcool superiores a 50\%. Em 22 de setembro de 1942, por meio do lançamento do Decreto-Lei n. 4.722, o governo declara a indústria alcooleira de interesse nacional e estabelece preços mínimos para o produto (NOVACANA, s/d, p. 1)

Diante do exposto sobre os cenários que impulsionaram os números da cana-de-açúcar, pode se dizer que o território brasileiro passou então por uma reestruturação produtiva no final da década de 1970, quando o cultivo da cana-de-açúcar ganhou números expressivos não somente na área plantada, mas também no que tange à sua produtividade que, em conjunto com a modernização da agricultura. teve-se um aumento substancial no rendimento por hectare. Mais tarde, a partir do século XXI, a dinâmica do setor canavieiro ganhou novos rumos com a inserção do setor sucroenergético e estabeleceu um aumento de forma vertiginosa na sua produção.

No que diz respeito ao complexo agroindustrial brasileiro, Marjotta-Maistro (2002) enfatizam que o setor sucroalcooleiro foi um dos que sofreu a maior e mais prolongada intervenção governamental. De acordo com a autora, competiu ao Instituto do Álcool e Açúcar (IAA) administrar esse setor entre 1933 a 1990. Por sua vez, a extinção do IAA estabeleceu uma nova dinâmica ao setor, com o início de um processo de gradativa desregulamentação, procedimento esse que veio a se materializar com a publicação da lei 12.490 de 16 de setembro de 2011, em que a Agência Nacional do Petróleo, Gás Natural e Biocombustíveis (ANP), passa a regulamentar o setor de biocombustíveis (TONIN; TONIN, 2014).

Diante deste contexto, Abreu et al. (1990) vão destacar que em 1971 foi criado o primeiro Programa Nacional de Desenvolvimento (I PND), o qual tinha como característica o incentivo ao setor exportador e a captação de investimento externo em setores de infraestrutura e na indústria de transformação, prioritariamente a energia elétrica, petróleo, transporte e comunicação.

A estratégia do agronegócio no início dos anos 2000 se caracterizou pelo retorno expressivo da tática de acumulação de capital. Neste sentido, o capital financeiro e a acumulação de capital são integradas ao capital aplicado em terras. Com isso estabelece-se um sistema de crédito para a agricultura, através de uma estratégia institucionalizada e, que tem uma ação de suma importância no que tange ao processo construtivo dos complexos agroindustriais. Essa estratégia do capital financeiro na agricultura, necessita estar atrelada com os mercados organizados de terras, crédito e os complexo agroindustriais. Para tanto, estes mercados precisam da regulação ou desregulamentação e das provisões estatais, o capital financeiro na agricultura só irá vingar, se ocorrer o chamado pacto de economia política entre as cadeias agroindustriais, grande propriedade e o Estado (DELGADO, 2012).

Ainda na questão dos marcos importantes que aconteceram no século XXI em relação ao setor canavieiro, Teodoro (2016, p. 25) aponta:

No ano de 2003 aconteceu um evento importante, que marcou a fase de desenvolvimento do setor, renomeado, a partir de então, como setor sucroenergético, que foi o início da produção e venda de veículos com motores flex fuel, isto é, que tem a capacidade de funcionar com gasolina e etanol.

Analisar a nova fronteira do setor sucroenergético é ressaltar um conjunto de processos que permite trabalhar a técnica no sentido da produção da vida, verificando a acumulação de condições que definem novas relações, que mostram novas configurações de regionalizações da globalização da economia, o que se dá a partir do sistema de objetos e de ações, sendo os fixos e fluxos (BERNARDES, 2013).

Nesse atual período do setor sucroenergético, as unidades produtivas se mostram cada vez mais atreladas com as técnicas modernas de plantio da cana-de-açúcar, bem como na produção do etanol e açúcar. Além desses fatores, destacam-se a comercialização, logística e a produção de energia, impondo novas relações de uso do território (VENCOVSKY, 2013).

A expansão expressiva da área e da produção de cana-de-açúcar a partir da década de 2000 foram promovidas principalmente pela conjunção entre as políticas do Estado brasileiro de estímulo às exportações do agronegócio (DELGADO, 2012) e da tentativa de condução de uma transição energética (PIRES DO RIO, 2011).

Delgado (2012) considera que para tal feito, teve uma reestruturação da economia do agronegócio e, desta forma, uma forte atuação do Estado na reativação do crédito rural para a produção agroexportadora, sendo essencial para o aumento das exportações da matéria-prima. Além do exposto, houve também o 
financiamento do BNDES para implantação e reestruturação das usinas e áreas produtivas (TEODORO, 2016). Destaca-se que neste momento passa a ter fusões e aquisições entre empresas do agronegócio, bem como uma articulação de pesquisas acerca dos órgãos responsáveis e empresas mundiais.

De acordo com Delgado (2012), versa-se sobre um "novo projeto de acumulação de capital no setor agrícola", sendo estimulado e organizado pela política macroeconômica e financeira do Estado brasileiro, em que beneficiou um grupo de empresas agroindustriais e grandes proprietários de terra (TEODORO, 2016).

Neste sentido, a quantidade de área plantada e também na produção em toneladas de cana-de-açúcar cresceu de forma significativa a partir dos anos 2000 (Tabela 1), sobretudo com essa reorganização do setor, que se reestruturou, produzindo não apenas açúcar e etanol, mas também a energia elétrica.

Tabela 1 - Área plantada, produção e rendimento médio de produção de quilos por hectares de cana-de-açúcar no Brasil, nos anos de 1990, 1995, 2000, 2005, 2010 e 2015

\begin{tabular}{cccc}
\hline Anos & $\begin{array}{c}\text { Área plantada } \\
\text { (ha) }\end{array}$ & $\begin{array}{c}\text { Volume de } \\
\text { produção (t.) }\end{array}$ & $\begin{array}{c}\text { Rendimento } \\
\text { médio de } \\
\text { produção kg/ha }\end{array}$ \\
\hline 1990 & 4.322 .299 & 262.674 .150 & 61,4 \\
1995 & 4.638 .281 & 303.699 .497 & 66,6 \\
2000 & 4.879 .841 & 326.121 .011 & 67,8 \\
2005 & 5.815 .151 & 422.956 .646 & 72,8 \\
2010 & 9.164 .756 & 717.463 .793 & 79,0 \\
2015 & 10.179 .827 & 750.290 .277 & 74,2 \\
\hline
\end{tabular}

Fonte - SIDRA - Produção Agrícola Municipal (1990 - 2015). Org.: Autores (2019).

A partir da tabela 1, nota-se que desde os anos de 1990 os números de cana-de-açúcar só vêm aumentando, tanto em termos de áreas plantada (ha), bem como no volume de produção (t.). No entanto, observa-se que entre 1990 a 2000, os números aumentam de forma modesta, e, de 2000 a 2015 os números aumentam de forma expressiva, o que reforça ainda mais a lógica do setor sucroenergético atuando no território brasileiro no século XXI.

Portanto, o Proálcool contribuiu para a produção de cana-de-açúcar no Brasil desde a sua implementação no ano de 1975, sendo uma política pública que influenciou diretamente para a expansão deste produto. E a partir dos anos 2000, essa reorganização do setor sucroenergético contribui ainda mais para o avanço da fronteira da cana-de-açúcar no território nacional, principalmente no Centro-Sul.

\section{A DINÂMICA DO SETOR SUCROENERGÉTICO NA MRG DE ITUIUTABA-MG}

A Microrregião Geográfica de Ituiutaba-MG teve seu espaço agrário se metamorfoseando ao longo dos anos, desde a produção agropecuária, as relações de trabalho e também as questões acerca do uso da técnica, ciência e informação.

Diante do exposto, destaca-se que a mudança na dinâmica da agricultura foi significativa a partir dos anos 2000 em relação à produção de cana-de-açúcar, ocasionando uma reestruturação produtiva nesta microrregião.

Salienta-se que o agronegócio, sobretudo o setor voltado para a produção de cana-de-açúcar, é norteado pela construção de uma Psicoesfera (SANTOS, 2008), que assegura e encaminha os investimentos e o estabelecimento de normas e leis para sustentar a conjuntura atual da atividade, apresentando números expressivos no período atual. Para que se tenha uma melhor compreensão dos números de cana-deaçúcar na MRG de Ituiutaba apresenta-se o gráfico 1, que revela os números da produção em toneladas de cana-de-açúcar nos anos de 1970, 1980, 1990, 2000, 2010 e 2016. 
Gráfico 1 - Produção de cana-de-açúcar na MRG de Ituiutaba nos anos de 1970, 1980, 1990, 2000, 2010 e 2016.

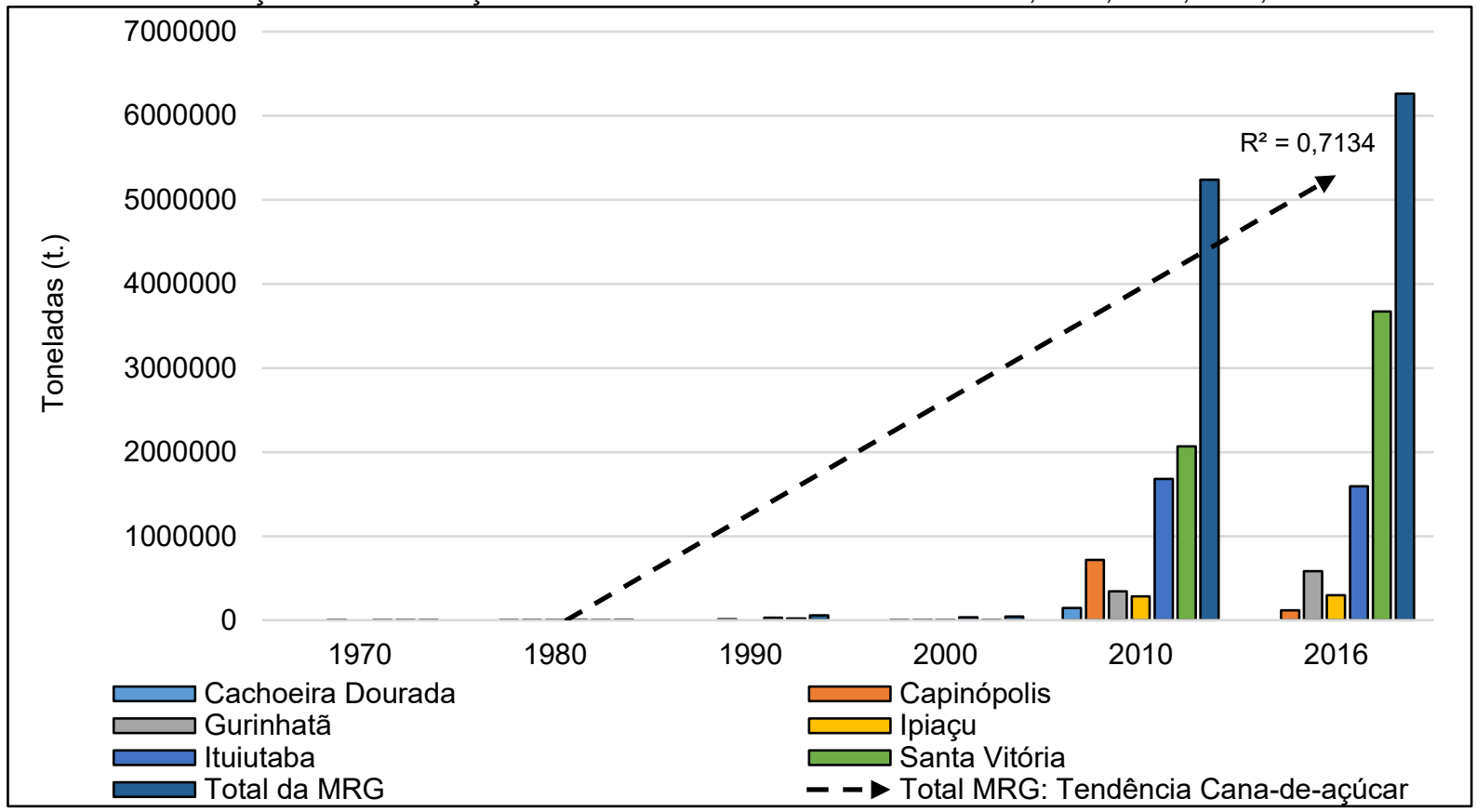

Fonte - SIDRA - Censo Agrícola (1970 - 1980); PAM (1990 - 2016). Org.: Autores (2019).

No Gráfico 1, optou-se por colocar o modelo estatístico de linha de tendência, onde aponta para uma tendência de crescimento para os próximos anos. O $\mathrm{R}^{2}$ possui um valor de 0,7134 , ou seja, quanto mais próximo do número 1 mais explicativo é o modelo, melhor ele se ajusta à amostra1.

A produção de cana-de-açúcar nos anos de 2010 e 2016 são tão significativos e discrepantes em relação aos demais anos, que, através do gráfico, a representação dos anos de 1970, 1980, 1990 e 2000 se mostram praticamente nulas em relação as de 2010 e 2016.

Elucida-se a dimensão dessa produção no ano de 2010 e 2016 na MRG de Ituiutaba, com toda sua disparidade das demais, não se traduz apenas no número total da MRG de Ituiutaba, mas em todos os municípios pertencentes à mesma.

Neste sentido, optou-se por elaborar e apresentar a Tabela 2, que demonstra os números da produção de cana-de-açúcar de todos os municípios da MRG de Ituiutaba nos anos de 1970, 1980, 1990, 2000, 2010 e 2016 para uma melhor compreensão desta produção.

Tabela 2 - Volume de produção (t.) de cana-de-açúcar na MRG de Ituiutaba nos anos de 1970, 1980, 1990, 2000, 2010 e 2016

\begin{tabular}{ccccccc}
\hline \multirow{2}{*}{ Municípios } & \multicolumn{7}{c}{ Anos } \\
\cline { 2 - 7 } & $\mathbf{1 9 7 0}$ & $\mathbf{1 9 8 0}$ & $\mathbf{1 9 9 0}$ & $\mathbf{2 0 0 0}$ & $\mathbf{2 0 1 0}$ & $\mathbf{2 0 1 6}$ \\
\hline $\begin{array}{c}\text { Cachoeira } \\
\text { Dourada }\end{array}$ & 0 & 1 & 0 & 0 & 146.080 & 0 \\
Capinópolis & 0 & 499 & 0 & 1.400 & 718.250 & 115.500 \\
Gurinhatã & 485 & 20 & 12.250 & 1.400 & 342.000 & 584.800 \\
Ipiaçu & 0 & 3 & 0 & 1.050 & 285.000 & 299.000 \\
Ituiutaba & 1.058 & 5.049 & 28.000 & 35.000 & 1.680 .000 & 1.592 .500 \\
Santa Vitória & 77 & 152 & 18.900 & 2.800 & 2.069 .360 & 3.672 .000 \\
\hline Total MRG & 1.620 & 5.724 & 59.150 & 41.650 & 5.240 .690 & 6.263 .800 \\
\hline Fonte- SIDRA - Censo Agrícola (1970-1980); PAM (1990-2016). Org.: Autores (2019).
\end{tabular}

\footnotetext{
1 De acordo com Oliveira (2013, p. 65) o " $\mathrm{R}^{2}$ ou coeficiente de determinação é uma medida de ajustamento de um modelo estatístico linear, ou seja, medida do sucesso da estimativa (tendência) dos valores observados. $R^{2}$ varia entre 0 e 1, indicando, em percentagem o quanto o modelo consegue explicar os valores observados".
}

$\begin{array}{lllll}\text { Caminhos de Geografia } & \text { Uberlândia-MG } & \text { v. 22, n. } 81 & \text { jun./2021 } & \text { p. 277-291 }\end{array}$ 
A partir dos números expostos na Tabela 2 nota-se que o volume de produção de cana-de-açúcar é algo que, no geral, cresceu ao longo dos anos, principalmente a partir do século XXI. No entanto, existem algumas variações que estão ligadas ao mercado nacional/internacional, bem como fechamentos de usinas sucroenergéticas e destilarias.

Diante da perspectiva do aumento da produção de cana-de-açúcar, devem-se destacar dois fatores que foram essenciais para tal processo. O primeiro é a ação do Estado, com as políticas governamentais que incentivaram a expansão da cana-de-açúcar, como o Proálcool, o Protocolo de Kyoto, os financiamentos do BNDES (construção de novas usinas e renovação dos canaviais), os estímulos para a produção de commodities, e a tecnologia flex fuel. O segundo motivo está ligado à inserção das usinas sucroenergéticas nesta região.

Dentro deste contexto, Michellon, Santos e Rodrigues (2008, p. 2) discorrem a respeito do Proálcool, enfatizando que,

\begin{abstract}
Em meio ao primeiro choque do petróleo em 1973, o governo brasileiro passa a buscar formas alternativas para reduzir a dependência do país ao combustível fóssil e amenizar os efeitos do choque na economia brasileira. Com a deterioração do balanço de pagamentos e aumento da inflação, causados pelo preço elevado do petróleo, o Brasil, que importava $80 \%$ da sua necessidade, se viu obrigado a buscar formas alternativas renováveis de combustível. Dentre vários programas propostos o que obteve maior êxito foi o Programa Nacional do Álcool - Proálcool, lançado em 1975, que visava a produção de álcool anidro de cana-de-açúcar, em destilarias anexas as usinas, para ser adicionado à gasolina. O programa nasce alicerçado em subsídios e financiamentos públicos, ficando a cargo do governo, através da Petróleo Brasileiro S/A - PETROBRAS, a compra, transporte, armazenamento, distribuição e mistura do álcool a gasolina, e também a determinação do preço de venda do produto.
\end{abstract}

O Proálcool tinha como objetivo o aumento da produção de safras de cana-de-açúcar atrelado com a capacidade industrial de transformação, ou seja, norteado com o próprio beneficiamento para então a obtenção do álcool e visando substituir o petróleo e seus derivados, em especial a gasolina, o que foi essencial para o aumento dessa produção de cana-de-açúcar no território nacional, bem como para a MRG de Ituiutaba.

No período mais recente, Castillo (2015) aponta para uma nova dinâmica para o setor sucroenergético brasileiro na década de 2000 , marcada, principalmente, pela significativa expansão da produção, para a qual poderíamos reconhecer alguns elementos, tais como: a expansão geral da produção de commodities no Brasil (pós 2000), as implicações do Protocolo de Kyoto (1997), a produção de automóveis flex fuel (2003) e o financiamento do BNDES (a partir de 1999). São esses os principais fatores para a expansão do setor sucroenergético no início do século XXI no Brasil e, consequentemente, em outras porções territoriais, como na MRG de Ituiutaba.

Outro aspecto já apontado no texto e que também tem uma participação expressiva nos números de produção de cana-de-açúcar na MRG de Ituiutaba, é a inserção das usinas sucroenergéticas, principalmente a partir de 2008, quando duas usinas de grupos estrangeiros começam suas atividades nesta região (os grupos Dow e BP Bunge).

Neste sentido, ao longo desse período (1970 - 2016), instalam-se as usinas de açúcar e álcool nos municípios pertencentes à MRG de ltuiutaba, as inauguradas no período do Proálcool, decretaram falência e foram compradas recentemente, as outras instaladas na década de 2000 , continuaram com suas operações sem interrupções até o momento. Desta forma, essas usinas tiveram grande participação nos números da cana-de-açúcar, especialmente no período atual, onde grande parte da área agricultável da microrregião encontra-se destinada à cana (Figura 2). Vale destacar que, até mesmo uma usina de beneficiamento desta matéria-prima instalada em outro município que não esteja na MRG de Ituiutaba, mas que inserida no entorno, pode acionar a produção de cana-de-açúcar dentro da MRG de Ituiutaba, tendo em vista que essas usinas vão em busca de grandes extensões de terras para o plantio da matéria-prima e consequentemente suprir sua demanda de moagem. 
Figura 2 - MRG de Ituiutaba-MG: Vista parcial de cultivo de cana-de-açúcar, 2019.

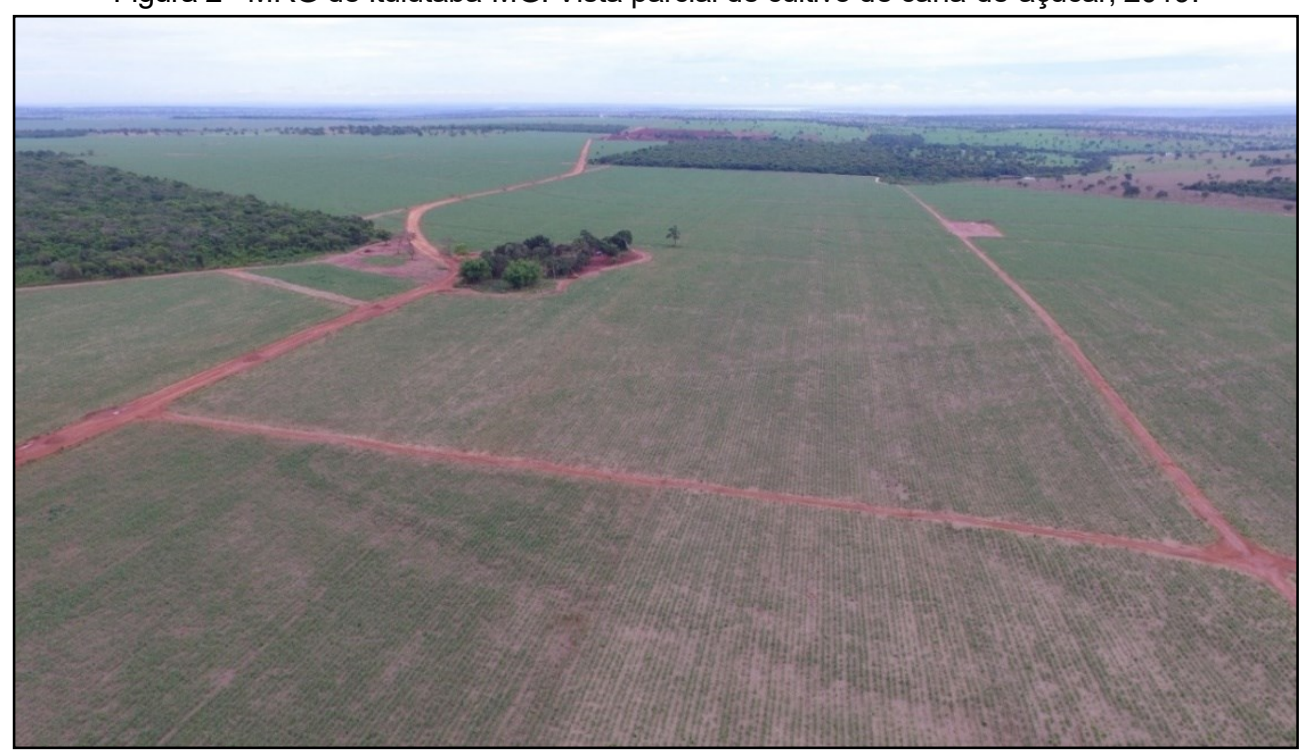

Foto - PENARIOL, R. Z. (2019).

No ano de 2019, a MRG de Ituiutaba dispôs de duas usinas sucroenergéticas em operação, uma inserida no município de Santa Vitória (usina Santa Vitória) e outra localizada no município de Ituiutaba (usina BP Bunge), sendo elas as responsáveis por quase toda a produção de cana-de-açúcar dessa microrregião. É importante destacar que a usina Vale do Paranaíba que se situa no município de Capinópolis foi comprada pelo grupo Japungu no final do ano de 2017, unidade que estava inativa desde o ano de 2014, com o seu decreto de falência, porém, suas operações iniciaram em janeiro de 2020.

Edificada em 2010, a usina Santa Vitória, controlada pelo grupo Dow, inicia-se uma parceria com o grupo japonês Mitsui em 2011, para projeto que visava a fabricação de plástico verde (a partir da cana-de-açúcar). No entanto, o projeto é frustrado e interrompe-se a parceria no ano de 2015. Atualmente a unidade Santa Vitória é controlada exclusivamente pela Dow.

A usina Santa Vitória (Figura 3) começou sua parceria com os produtores locais em 2008 para o plantio de cana-de-açúcar, e nos dias atuais, estima-se que 36 mil hectares plantados de cana-de-açúcar são destinados ao beneficiamento da usina de Santa Vitória. Além disso, a usina possui capacidade de moagem de 2,7 milhões de toneladas de cana-de-açúcar por safra, além de 240 milhões de litros de etanol hidratado (USINA SANTA VITÓRIA, 2018).

Figura 3 - MRG de Ituiutaba-MG: Vista aérea da usina de Santa Vitória, 2019.

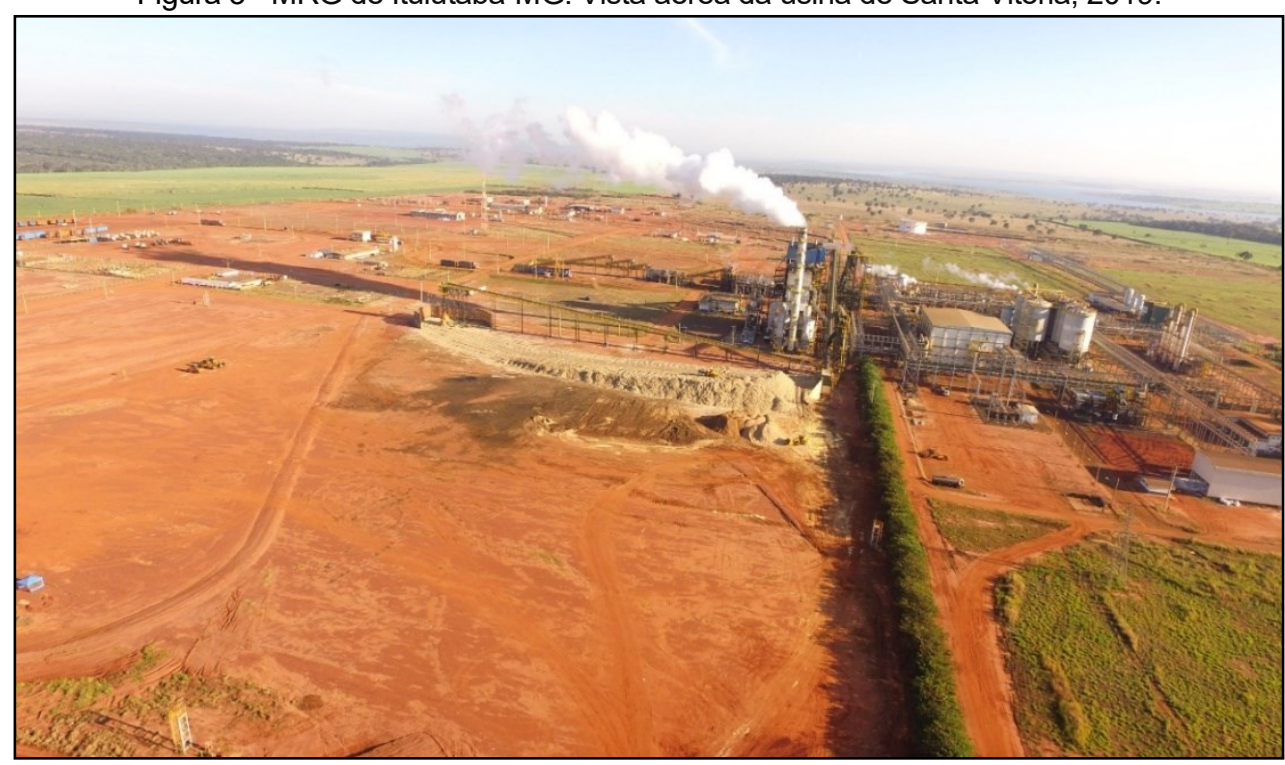

Foto - PENARIOL, R. Z. (2019). 
A instalação da usina de Santa Vitória proporcionou um aumento na produção de cana-de-açúcar no município, bem como influenciou outros municípios no que tange à produção de cana-de-açúcar, conforme pode-se verificar na figura 4 .

Figura 4 - MRG de Ituiutaba-MG: Municípios acionados na produção de cana-de-açúcar pela usina Santa Vitória, 2019.

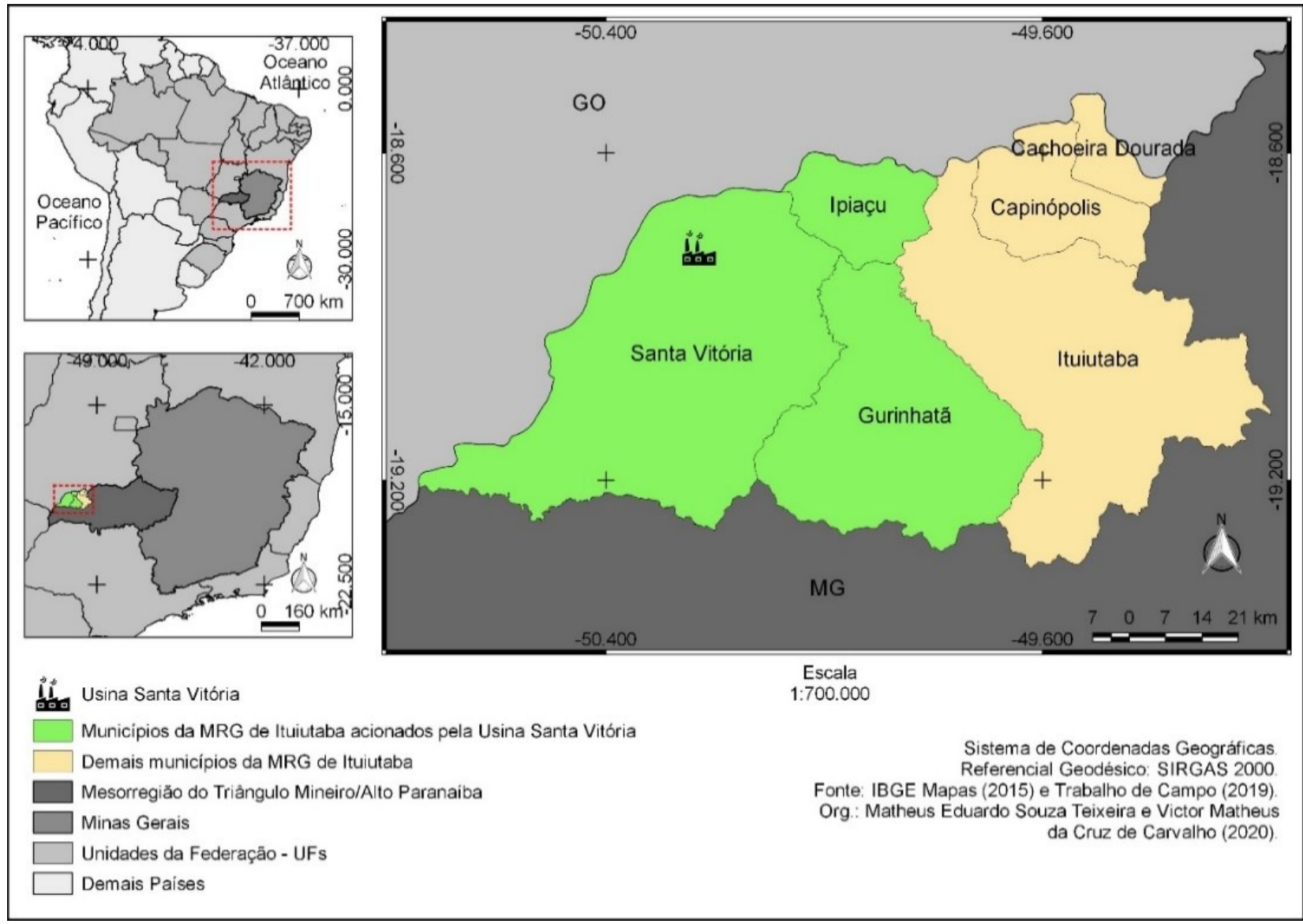

Neste sentido, a figura 4 revela que a usina de Santa Vitória, além do município em que a usina está inserida, também aciona outros dois municípios que pertencem à MRG de Ituiutaba, sendo Gurinhatã e Ipiaçu, haja vista que normalmente contratos de safras são fechados nesses municípios e/ou arrendamentos de terras. Ressalta-se que a usina de Santa Vitória ainda arrenda terras no município de São Simão-GO, que não pertence à MRG de Ituiutaba.

Além da usina de Santa Vitória, a microrregião ainda possui outra usina sucroenergética, esta inserida no município de Ituiutaba (usina BP Bunge), e que também culminou para um aumento na produção de canade-açúcar. Destaca-se que esse aumento na produção está associado à questão da disponibilidade de mão de obra, terras mais baratas, condições edafoclimáticas favoráveis, entre outros aspectos.

Destaca-se que a usina BP Bunge Bioenergia possui capacidade de moagem de 2,5 milhões de toneladas de cana-de-açúcar por safra, com suas operações voltadas para o açúcar (VHP e cristal), etanol (anidro e hidratado) e energia elétrica (BP BRASIL, 2018).

O aumento na produção de cana-de-açúcar na microrregião ao longo dos anos foi algo nítido e esses números estão atrelados ao fato dessas usinas sucroenergéticas estarem inseridas nessas localizações. Desta maneira, o município de Ituiutaba teve um aumento substancial referente às áreas plantadas e também no volume de produção dessa matéria-prima. 
No entanto, a usina BP Bunge também influencia na dinâmica da produção de cana-de-açúcar de outros municípios, assim como a usina de Santa Vitória. Porém, a usina BP Bunge, mesmo com uma capacidade de moagem menor que a usina Santa Vitória, exerce ainda influência em outros municípios além dos pertencentes à MRG de Ituiutaba, fato que ocorre pela disponibilidade de terras em Ituiutaba, uma vez que a soja ocupa uma parcela considerável da área agricultável do município. A figura 5 mostra a influência da usina BP na MRG de Ituiutaba.

Figura 5 - MRG de Ituiutaba-MG: Mapa dos municípios acionados na produção de cana-de-açúcar para usina BP Bunge, 2019.
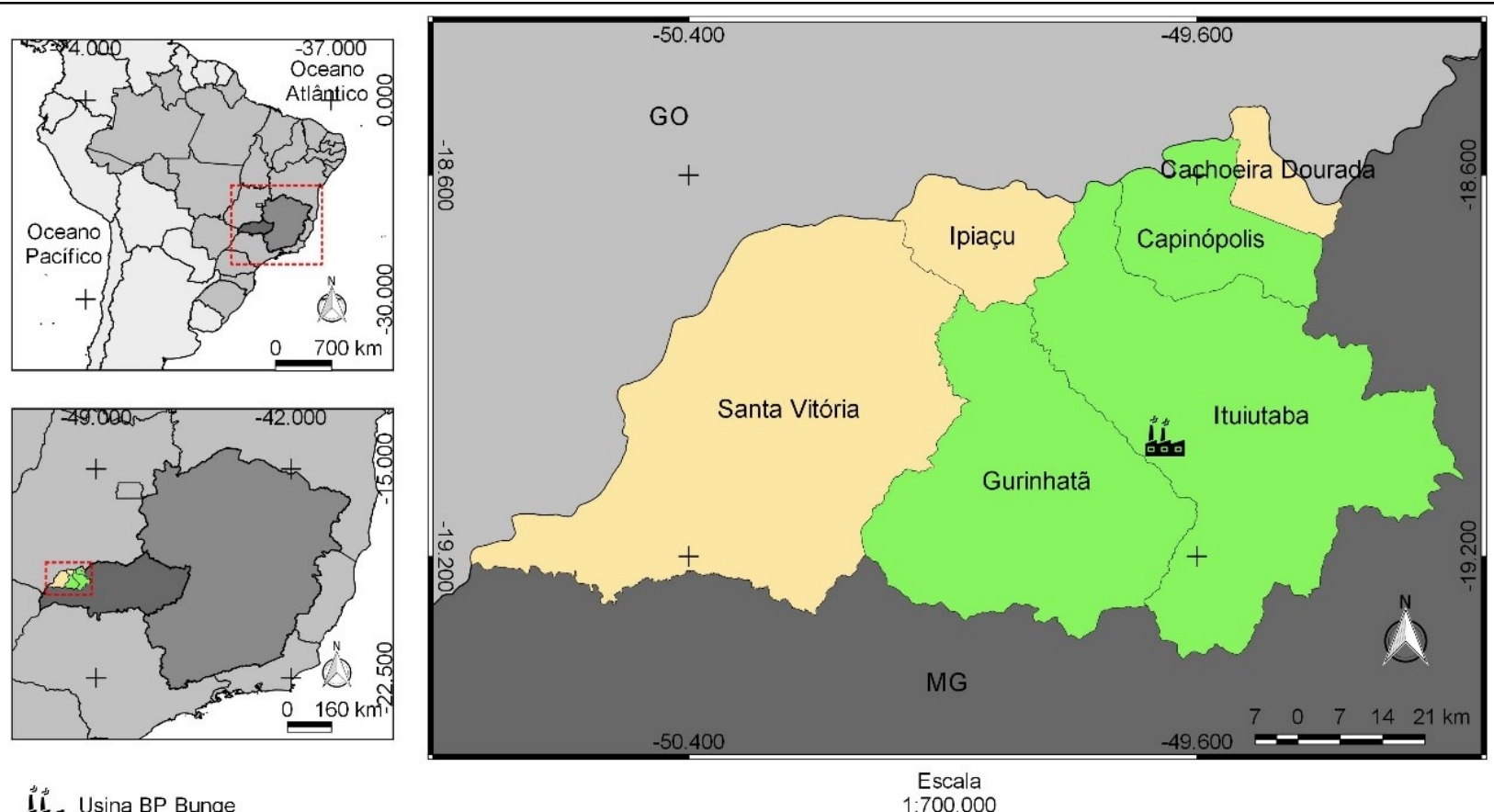

Uึ. Usina BP Bunge

$1: 700.000$

Municípios da MRG de Ituiutaba acionados pela Usina BP Bunge

Demais municipios da MRG de ltuiutaba

Sistema de Coordenadas Geográficas

Referencial Geodésico: SIRGAS 2000

Mesorregião do Triângulo Mineiro/Alto Paranaiba

Minas Gerais

Unidades da Federação - UFs

Fonte: IBGE Mapas (2015) e Trabalho de Campo (2019).
Org.: Matheus Eduardo Souza Teixeira e Victor Matheus da Cruz de Carvalho (2020)

A partir das informações obtidas na figura 5, a mesma nos mostra que a usina BP Bunge além de acionar a produção de cana-de-açúcar no município de Ituiutaba, também possui participação nos municípios de Gurinhatã e Capinópolis, todos esses pertencentes à MRG de Ituiutaba. A usina BP Bunge também influencia na produção da cana-de-açúcar em outros municípios que não estão inseridos na MRG de Ituiutaba, sendo eles: Monte Alegre/MG, Canápolis/MG e Prata/MG.

A usina BP Bunge (figura 6), que se localiza no município de Ituiutaba, teve um papel fundamental para os números na produção da cana-de-açúcar. Porém, deve-se salientar que antes mesmo das operações da usina BP Bunge, outra usina inserida no município de Canápolis - MG (usina Triálcool) acionava os municípios da MRG de Ituiutaba, principalmente o município de Ituiutaba, devido sua proximidade. No entanto, tal usina decretou falência 2015, e recentemente foi adquirida pelo grupo CMAA, com suas operações iniciadas em 2020. Ou seja, o histórico de usinas sucroenergéticas na MRG de Ituiutaba não é algo recente. Vale destacar que a usina sucroenergética BP Bunge inicia suas atividades no ano de 2011,

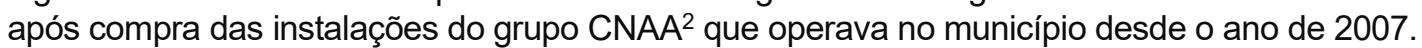

${ }^{2}$ A CNAA foi formada em 2007, através de uma joint venture entre o grupo Santelisa Vale - posteriormente incorporado pela Louis Dreyfus Commodities - e fundos de investimentos estrangeiros, entre os quais Riverstone e Carlyle Group, além do Goldman Sachs, Global Foods e Discovery Capital (O GLOBO, 2007).

$\begin{array}{lllll}\text { Caminhos de Geografia } & \text { Uberlândia-MG } & \text { v. 22, n. } 81 & \text { jun./2021 } & \text { p. 277-291 }\end{array}$


Figura 6 - MRG de Ituiutaba-MG: Vista aérea da usina BP Bunge, 2019.

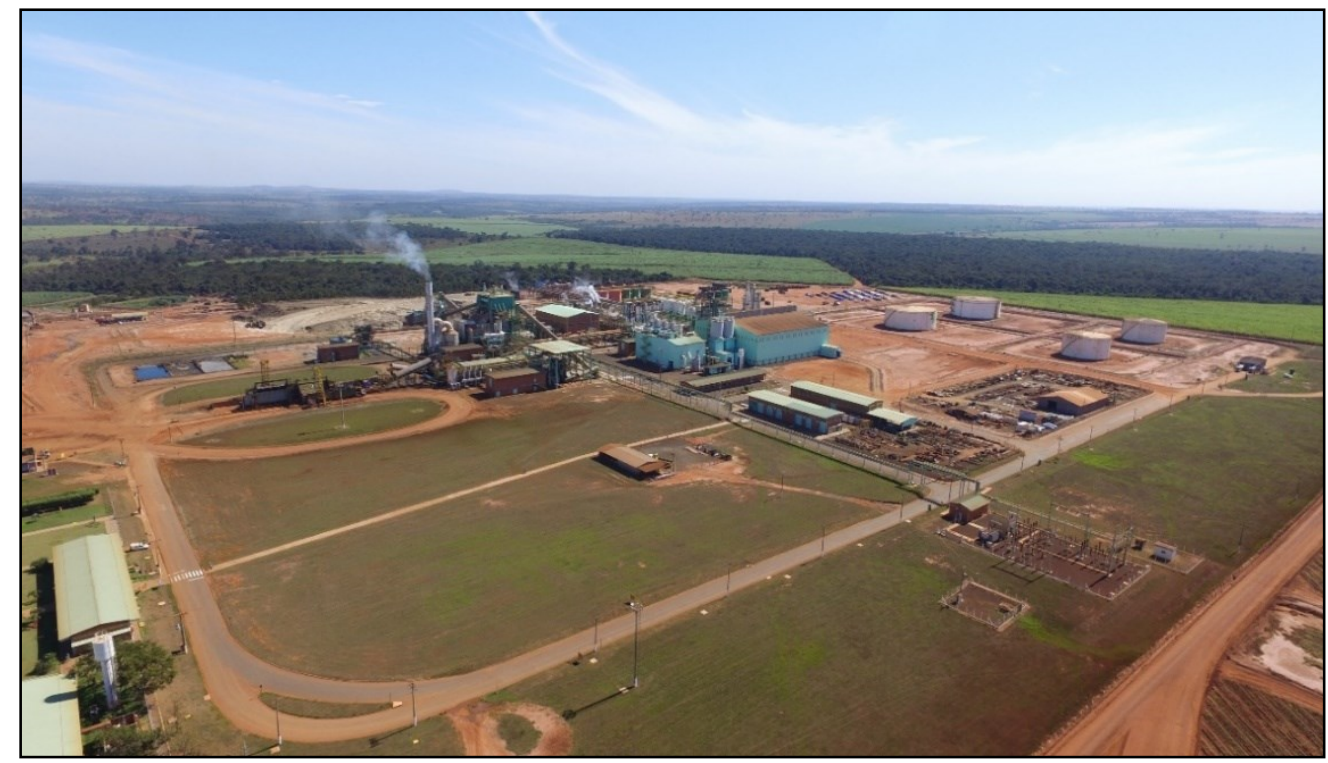

Foto - PENARIOL, R. Z. (2019).

Portando, a presença de usinas sucroenergéticas afeta a estrutura agrícola do município em que estão inseridas, bem como os que se encontram ao seu entorno, influenciando os produtores a optarem por arrendarem suas terras para as usinas, sobretudo em função do poder de barganha das usinas e a consequente renda fixa mensal do arrendamento, que geralmente, apresenta-se de forma menos vulnerável às intemperes do mercado, principalmente quando comparado à outras atividades agropecuárias, como a pecuária bovina leiteira - atividade sujeita a preços instáveis durante o ano.

\section{CONSIDERAÇÕES FINAIS}

A modernização da agricultura que foi imposta principalmente através da Revolução Verde, modificou a forma de cultivo, uma vez que possibilitou uma gama tecnológica na sua produção, onde a agricultura de pequeno porte e as que não empregavam a tecnologia decaíram, já as monoculturas extensivas, sobretudo as que dependiam bastante das tecnologias, tiveram crescimento. Com isso, modificou-se o espaço agrário, ressaltando-se principalmente as monoculturas de soja, cana-de-açúcar e milho.

Além da modernização da agricultura, as políticas públicas tiveram um papel fundamental no que tange aos aspectos da expansão das commodities, sendo o ponto de partida para uma reestruturação produtiva no território brasileiro.

Assim, a ação do Estado é de fundamental importância para nortear a dinâmica de produção de uma região. Neste sentido, destaca-se que no século XX, o Proálcool teve um papel essencial para a expansão da canade-açúcar no território nacional, bem como na MRG de Ituiutaba, que também teve seus números aumentados a partir da implantação dessa política pública, mas que só ia ter seus números elevados de forma significativa a partir dos anos 2000.

Neste sentido, o início do século XXI é marcado pela expansão significativo do setor sucroenergético em diversas porções territoriais do Brasil, que teve alguns fatores preponderantes, como: a ampliação da produção de commodities no Brasil (2000), dos compromissos do país assumidos no Protocolo de Kyoto (1997), a inserção no mercado interno dos automóveis flex fuel (2003), bem como os fartos recursos disponibilizados ao setor através de financiamentos do BNDES (a partir de 1999).

A estrutura produtiva agrícola na MRG de Ituiutaba passou por uma significativa modificação, ocasionada principalmente pelas instalações das usinas sucroenergéticas, em que favoreceram amplamente para o aumento da produção de cana-de-açúcar. 
Acompanhando a expansão da cana-de-açúcar em nível nacional, diante das políticas públicas, sobretudo pelo Proálcool, a MRG de Ituiutaba iniciou a produção de cana no final da década de 1980. A instalação de uma usina no município de Canápolis (ainda que não pertencente à microrregião em estudo), influenciou o cultivo dessa matéria-prima nos municípios limítrofes, principalmente Ituiutaba.

No decorrer dos anos, especificamente no século atual, com a expansão da cana no Brasil Central, adentrando à região do Triângulo Mineiro/Alto Paranaíba, a MRG de Ituiutaba conheceu uma significativa inserção do cultivo de cana-de-açúcar, acompanhado da incorporação de agentes do setor sucroenergético, alguns estrangeiros, como o grupo Dow e BP Bunge. Desta forma, a região Ituiutaba, reconhecendo seu papel na Divisão Territorial do Trabalho, teve, no século atual, sua área plantada de cana ampliada de forma significativa, indicando a rapidez com que se aumentou o cultivo.

Portanto, a expansão do setor sucroenergético na MRG de Ituiutaba está estritamente vinculada com as ações do Estado, que através das políticas governamentais, estimularam a produção de cana-de-açúcar em várias partes do território nacional, especialmente na região Centro-Sul. Além disso, a presença das usinas sucroenergéticas na região também corrobora para um aumento da produção de cana-de-açúcar nos municípios pertencentes à MRG de Ituiutaba, não se limitando aos municípios em que as unidades estão inseridas, mas também nos municípios do entorno, fato que ocorre pela necessidade de captura de grandes extensões de terras para suprir a demanda de processamento de sua unidade industrial.

A partir destas constatações, conclui-se que esta pesquisa contemplou o objetivo proposto, uma vez que foi possível analisar de que forma ocorre a expansão da cana-de-açúcar na MRG de Ituiutaba e os principais agentes causadores desta ação, bem como entender as implicações territoriais decorrentes deste processo. Para novas pesquisas a serem exploradas, recomenda-se analisar quais as principais atividades agrícolas cederam espaços para a expansão do setor sucroenergético na MRG de Ituiutaba e como ficaram essas atividades para os pequenos e médios produtores rurais.

\section{AGRADECIMENTOS}

Pesquisa financiada com recursos do edital Demanda Universal da Fundação de Amparo à Pesquisa do Estado de Minas Gerais - FAPEMIG (Nº01/2017), registrado no processo APQ-01562-17. Neste sentido, os autores agradecem à FAPEMIG pelo incentivo ao desenvolvimento da pesquisa e sua divulgação.

\section{REFERÊNCIAS}

ABREU, M. P. et al. A Ordem do Progresso: Cem anos de política econômica republicana 18891989. Rio de Janeiro, Editora Campus, 1990.

BERNARDES, J. A. Metamorfoses no setor sucroenergético: emergência de contradições. In: Júlia Adão Bernardes, Cátia Antônia da Silva, Roberta Carvalho Arruzzo (org.). Espaço e energia: mudanças no setor sucroenergético. 1ed.Rio de Janeiro: Lamparina, 2013, v. 1, p. 143-155.

BP BRASIL. Nossas Operações - Ituiutaba. 2018. Disponível em: http://www.bp.com/pt_br/brazil/oque-fazemos/biocombustiveis/nossas-operacoeshtml. Acesso em: 11 fev. 2019.

CASTILLO, R. Dinâmicas recentes do setor sucroenergético no Brasil: competitividade regional e expansão para o bioma Cerrado. Revista GEOgraphia, 17, n 35, 2015. Disponível em: http://www.geographia.uff.br/index.php/geographia/article/view/877. Acesso em: 06 maio 2018. https://doi.org/10.22409/GEOgraphia2015.1735.a13730

CRUZ, C. H. de B. et al. Universidades e empresas: $\mathbf{4 0}$ anos de ciência e tecnologia para o etanol brasileiro. In: Luís Augusto Barbosa Cortez (org.). São Paulo: Blucher, 2016. 224 p.

DELGADO, G. C. Do "capital financeiro na agricultura" à economia do agronegócio: mudanças cíclicas em meio século (1965-2012). Porto Alegre: UFRGS, 2012. 144 p.

INSTITUTO BRASILEIRO DE GEOGRAFIA E ESTATÍSTICA - IBGE. Censo Agrícola de Minas Gerais. Rio de Janeiro, 1960. 
Censo Agropecuário de Minas Gerais. Rio de Janeiro, 1970.

Censo Agropecuário de Minas Gerais. Rio de Janeiro, 1980.

Censo Agropecuário de Minas Gerais. Rio de Janeiro, 1990.

Pesquisa Agropecuária Municipal - PAM. 1990, 2000, 2010. Disponível em:

http://www.sidra.ibge.gov.br/bda/popul/default.asp?z=t\&o=25\&i =P. Acesso em: 02 abr. 2018.

Cidades@. 2010. Disponível em: http://cidades.ibge.gov.br/xtras/

perfil.php?lang=\&codmun=313420\&search=minas-ger ais|ituiutaba. Acesso em: 12 mar. 2019.

Geociências. 2015. Disponível em:

https://downloads.ibge.gov.br/downloads_geociencias.htm. Acesso em: 16 mar. 2019.

LOCATEL, C.; AZEVEDO, F. F. de. Desenvolvimento rural, Política Nacional de Biocombustíveis e o mito da inclusão social no campo brasileiro. Diez años de cambios en el Mundo, en la Geografía y en las Ciencias Sociales, 1999-2008. Actas del X Coloquio Internacional de Geocrítica, Universidad de Barcelona, 26-30 de mayo de 2008. Disponível em: http://www.ub.edu/geocrit/-xcol/313.htm. Acesso em: 12 de abr. de 2019.

MARJOTTA-MAISTRO, M. C. Ajustes nos mercados de álcool e gasolina no processo de desregulamentação. Piracicaba, 2002. Tese (Doutorado), Escola Superior de Agricultura Luiz de Queiroz, Economia Aplicada, Piracicaba, 2002.

MICHELLON, E.; SANTOS, A. A. L.; RODRIGUES, J. R. A. Breve Descrição do Proálcool e perspectivas futuras para o etanol produzido no Brasil. Revista Sociedade Brasileira de Economia, Administração e Sociologia Rural, 2008. Disponível em:

http://www.sober.org.br/palestra/9/574.pdf. Acesso em: 08 abr. 2019.

MORAES, M. A. F. D. de. As profundas mudanças institucionais ao longo da história da agroindústria canavieira e os desafios atuais. Economia Aplicada, São Paulo, v. 11, n. 4, p. 555557, out./jan. 2007. https://doi.org/10.1590/S1413-80502007000400005

NASTARI, P. M. The role of sugarcane in Brazil's history and economy. 1983. Ph.D. Dissertation, lowa State University, Ames, 1983. Disponível em:

https://lib.dr.iastate.edu/cgi/viewcontent.cgi?article=9947\&context=rtd. Acesso em: 10 de abr. 2019.

NOVACANA. Novacana Data. 2018. Disponível em: https://www.novacana.com/data/. Acesso em: 11 de abr. 2019.

O GLOBO. Economia. 2007. Disponível em: https://oglobo.globo.com/economia/louisdreyfusassume-santelisa-planeja-ipo-3129469. Acesso em: 16 jun. 2018.

OLIVEIRA, H. C. M. de. Urbanizações e Cidades: análises da microrregião geográfica de Ituiutaba (MG). 2013. 431 f. Tese (Doutorado em Geografia) - Instituto de Geografia, Universidade Federal de Uberlândia, Uberlândia, 2013. Disponível em:

https://repositorio.ufu.br/bitstream/123456789/15977/1/UrbanizacaoCidadesAnalise.pdf. Acesso em: 10 jun. 2017.

PIRES DO RIO, G. A. Escalas de política energética: o programa nacional de biodiesel. In: BERNARDES, J. A \& ARACRI, L. A. S. Novas fronteiras do biodiesel na Amazônia: Limites e desafios da incorporação da pequena produção agrícola. Rio de Janeiro: Arquimedes, 2011. 27 - 46 p.

Santa Vitória Açúcar e Álcool. Sobre a usina Santa Vitória. 2018. Disponível em: http://www.ussantavitoria.com.br/?p=2854. Acesso em: 11 abr. 2019.

SANTOS, M. A natureza do espaço. 4 ed. 4. reimpr. São Paulo: Edusp, 2008.

TEODORO, M. A. Concentração econômica do capital e especialização territorial produtiva no setor sucroenergético na região de Iturama (MG). 2016. 129 f. Dissertação (Mestrado em 
Geografia). Instituto de Geociências e Ciências Exatas, Universidade estadual paulista "Júlio de Mesquita Filho", Rio Claro, 2016.

TONIN, J. R.; TONIN, J. M. Do Proálcool ao "Próetanol": novos desafios na produção do etanol brasileiro. Informe Gepec, Toledo, v. 18, n. 1, p. 61-76, jan./jun. 2014. Disponível em: http://erevista.unioeste.br/index.php/gepec/article/view/7549. Acesso em: 10 de abr. 2019.

VENCOVSKY, V. P. Setor sucroenergético: a emergência de um novo período. In: Júlia Adão Bernardes; Catia Antonia da Silva; Roberta Carvalho Arruzzo. (Org.). Espaço e energia: Mudanças no paradigma sucroenergético. 1 ed. Rio de Janeiro: Lamparina, 2013, p. 51-62.

Recebido em: 23/06/2020

Aceito para publicação em: 22/02/2021 